\title{
Latina Narrative as Postmodernist Ethnic Commodity: New Sites of Rupture, Ambivalence and Playfulness
}

\author{
Antonia Domínguez Miguela \\ Universidad de Huelva
}

During this decade, some Latina authors such as Sandra Cisneros, Ana Castillo, Cristina García, Julia Alvarez, Judith Ortiz Cofer and Esmeralda Santiago have received wide critical attention and their works have been published by mainstream publishing houses. The sudden recognition of their literary production should be approached from a critical perspective that bears in mind the causes and motives of the recent demand for this kind of ethnic literature. This interest responds to political and cultural goals that relate to the new era of multiculturalism and its attempts to turn these narratives in mere literary and cultural commodities. Thus, they become exotic products that provide color and spice to contemporary American literature, yet always within the limits of cultural and political propriety.

Firstly, there is a very important issue that needs to be addressed: American attitudes towards Latin American countries as important sources of Latino writers' cultural heritage. The relation between Latin America and the United States is unequivocally complex and characterized by a long history of unbalance between them that elucidates the centrality and neo-colonialist power that the northern country has in apparent contrast to the marginality and dependency that distinguishes most Latin American countries. North American discourse regarding Latin America has always sought to depict Latin America as the Other, defining it as the negative of what is American and Anglo-Saxon. With a past of political violence, repressive governments, human rights violations, massacres and evident inability for self-control, Latin American countries have been constantly feared by the United States. For a country that was founded as the land of liberty, justice, democracy and which has proclaimed itself the world's defender, Latin America represents that obsessive shadow from where evils may come to infect blessed America.

The most recurrent ways to contain Latin American influence in the North has been the creation of a manipulated definition and representation of Latin American people, their culture and history. A number of stereotypes had been created and spread about the inferiority of a people that is dominated by their passions and impulses. ${ }^{1}$ Regarding politics, the United States has always justified their intervention in Latin American politics under the premise of their apparent inability at self-government and their recurrent failures to stabi-

\footnotetext{
${ }^{1}$ The Latino subject, in a similar way to that of the colonized subject approached by Homi Bhabha, becomes a Stereotype that has its given function in the dominant discourse as Bhabha explains: "The fetish in stereotype gives access to an 'identity' which is predicated as much on mastery and pleasure as it is on anxiety and defence ... the scene of fetishism is also the scene of the reactivation of primal fantasy the subject's desire for a pure origin that is always threatened by its division" (75).
} 
lize and develop their national economies. This intervention has always been a very subtle way to mask a neo-colonialist relation between the United States and Latin America that has increasingly become an excellent site to do business as these countries become consumer of American goods and products while their natural or human resources are depleted for the benefit of American companies.

During the second half of this century, postmodern discourse in Latin America has attempted to confront the dominant discourse of the United States and European countries that had until now represented and defined them. The Latin American literary boom was a clear example of how literature could help rewrite the history of Latin America from within. Though the cultural influence of European cultures and languages could not be completely erased, a new system of representation was necessary to faithfully portray the Latin American experience. The magic realist literature was a powerful instrument at the hands of these writers striving to redefine themselves, their cultures and nations. However, these ambitious and successful literary works were commodified and the primary goals they pursued were substituted by a trend of commodification in American culture. The Latin American narratives have become objects of desire, attractive accounts of marvelous events in a land of enchantment. The darker side of Latin America was preserved as an ultimate excuse for political intervention while Latin American culture and reality was manipulated and appropriated as a commodity, an exotic object of consumption.

The most powerful critique of this condescending and manipulative attitude towards Latin American countries and their culture, has recently come from an emerging literature created by descendants of Latin American people living in the United States. As people whose experience has been inevitably affected by both cultures, they have become privileged observers who are able to discern possible misrepresentations of the Other by either culture, thereby raising interesting questions about American multiculturalism and interethnic relations. We have chosen narratives by Latina writers because it is in their works were criticism in both directions can be more easily observed. This is due to their condition as individuals who suffer double discrimination because of their race and their gender. By fighting against the attempts at softening and domesticating the Latino presence with multiculturalist "festivals of diversity," Latina narrative takes part in an important project where contemporary writers not only reassess their ethnic and cultural heritage in new ways once that the confrontation and bigotry of the sixties has been counteracted by Estate multiculturalism. They are also addressing political issues relevant to the new situation concerning race, class and gender.

This paper tries to briefly analyze some narratives by Latina writers paying especial attention to their postmodern quality exemplified in the way in which they retain their subversive political message under the cover of fashionable ethnic literature wrapped in pseudo-magic realist plots, 'very ethnic' characters and exotic cultural practices and landscapes. The achievement of these authors is precisely contained within the strategies that have been used to create double meanings, submerged re-interpretations of ethnicity in American society. Among these strategies we can mention the parodic use of the Hispanic and magic realist tradition, the multiple and ambivalent readings allowed for readers of 
different ethnic and social backgrounds, the manipulation and tropicalization of the English literary language, and the challenge of traditional ideas of culture, ethnicity and nationality. Therefore, these narratives further destabilize contemporary debates on American culture and society becoming subtle means for containment and resistance.

The marketing of ethnic literature is most noticeable in the case of Latina writers who have been witness to an incredible interest from publishing houses that had ignored their work for a long time. Similarly to other ethnic writers such as African American and Chinese American female writers, Latinas' experience as ethnic women in America supplied their works with exotic accounts of a different culture and its practices that were the more attractive to Anglo readers. They had been disenchanted by the frequently disturbing exercises in self-referential narratives of postmodern writers of the $60 \mathrm{~s}$ and $70 \mathrm{~s}$, and by the too familiar plots of other 'mainstream' narratives that never provided enough excitement to the common American reader eager to find relief from daily stress in the different experience of the ethnic other.

This demand for something different and new emerges at the same time that the national institutions design new ways to cope with the increasing power of minorities strengthened after the 60s. As Shelby Steele referred to them in a controversial article on Harper's Magazine, these "grievance groups" had become "nations unto themselves" (47) in the 70s and 80 s to the extent that they no longer claimed equal rights but they demanded and were given preferential treatment (affirmative action). Yet, this institutional strategy was not completely successful and had to cope with ethnic conflict among minorities and the nonethnic population who apparently suffered the negative effects of affirmative action as a new way of inequality. Therefore, the scheme of a multicultural nation where ethnic diversity emerges as a positive element, substitutes the idea of an already simmering melting pot. However, what at first seemed to be a democratic and harmonious way to cope with ethnic difference, has proved to be a mere plot "in which the mainstream exhibits an interest in diversity as a means of containing the ruptural elements in various social movements" and where the words 'diversity' and 'multiculturalism' merely "enhance and reify the lives of minorities in the United States" (McCracken 8).

Thus, Latina narratives became successful marketable products of the era of multiculturalism as long as they fulfilled a minimum of what the readership asked for. These works are supposed to respond to what we could call "postmodern ethnicity" perceptively described by Henry Louis Gates as "all the colors of the world, none of the oppression" (186). Some Latino/a writers have been trying to overcome capitalistic attempts at transforming them in mere commodities, consumer goods, literary fashions, while at the same time they cannot ignore the advantages of getting a wider readership and subsequently, more critical and social attention.

This sudden mainstreaming of ethnic writers who were completely invisible until now, has provoked hot debates among critics, readers and writers. Nowadays, there is an ongoing discussion of the permanence and function of this literature as it becomes a mere product demanded by the market. At the same time, this new ethnic literature has a peculiar relationship with postmodernist and postructuralist critical trends. For instance, while on 
the one hand ethnic literature shares with postmodernist trends a concern with de-centering of western ideologies and their traditional systems of representation of the other, on the other hand it is centered on the subject in evident contrast with the dissolution of the subject promulgated by postmodernist criticism and it also takes the risk of perpetuating a discourse on otherness and difference as they try to achieve recognition by the institutions.

Latina narrative, similarly to other Latino writers but with the additional concern with gender issues, makes use of a number of literary resources to counter a dominant discourse that tries to manipulate difference for its own benefit, domesticating it, accepting their presence with some restraint. As professor Ellen McCracken points out, "the creation of 'minority commodities' attempts to reabsorb writers and texts into mainstream ideology as desirable elements of postmodernity that can be purchased and, to some degree, possessed" (12). We will try to see very briefly how Latina writers like Ana Castillo, Esmeralda Santiago, Judith Ortiz Cofer, and Julia Alvarez take advantage of their mainstreaming to confront cultural and political issues in a subtle and ambiguous terrain. Their texts reveal themselves as powerful instruments of defamiliarization and deconstruction of preconceived ideas about Latinas and as a harsh critique of the institutions that have perpetuated their misrepresentation. The text plays with Anglo readers who are apparently given what they desired first but who is unconsciously confronted with their own misconceptions about the ethnic other. Tropicalization from above is gradually substituted by a tropicalization from below that in its first stages it consciously uses the mechanisms of definition of the dominant discourse to invalidate them as the narration progresses.

The tropicalization of the English language in these literary works is especially interesting for its many creative possibilities and its subtle challenge to the dominant discourse. Tropicalization consists of the manipulation of English so that it becomes impregnated by a cultural and linguistics Latino substratum while, as Frances Aparicio observes, it also implies "a transformation and rewriting of Anglo signifiers from the Latino cultural vantage point ... new possibilities for metaphors, imagery, syntax, and rhythms that the Spanish subtext provides U.S. literary English" (201-3). The addition of new signifiers with a Latino substratum modifies the text's reception to the extent that it may defamiliarize Anglo readers from their native language. What at first sight may look like lack of linguistic competence, is, in fact, creative and innovative experimentation with literary language. This new discourse is as Homi Bhabha points out, "a discourse at the crossroads of what is known and permissible and that which though known must be kept concealed; a discourse uttered between the lines and as such both against the rules and within them" (89). For instance, while an Anglo reader may not understand the real complexity of a message or may be unwillingly invited to accept a harsh critique on American society, a bilingual Latino reader is able to establish a sort of complicity with the writer, thereby making the message more powerful.

Sandra Cisneros's work Woman Hollering Creek, stands out for its brilliant linguistic games such as her peculiar literal translations of Bolero lyrics in the story "Tin Tan Tan." In the title of the story "Salvador Late or Early," we can observe an inappropriate use of English since the correct sentence would be "sooner or later," however, the writer has opted 
for a literal translation of the phrase "tarde o temprano" whose meaning can be easily understood while at the same time it shows a startling influence of the underlying Spanish. This is also what we find in expressions like "I am without shame" (32), that defamiliarize English by making more reference to the particular Spanish expression "sinvergüenza" rather than the English one "I am shameless." Cisneros is especially creative and innovative when she makes up words that become literal winks at the bilingual reader. This is obvious when we notice, for instance, that a company is named "LA CUCARACHA APACHURRADA PEST CONTROL" (138).

So Far from God, by Ana Castillo, is another brilliant stylistic exercise in which literary language becomes permeated by different literary traditions such as the Latin American or the Spanish. This is what we often observe in the rocambolesque titles of many chapters, that clearly reminds us of El Quijote: "Of the Hideous Crime of Francisco el Penitente, and His Pathetic Calls Heard Throughout the Countryside as His Body Dangled from a Piñón like a Crow-Picked Pear" (190). Castillo also defamiliarizes literary English through the use of Spanish syntactic structures such as the double negation and the calque of expressions and idioms from Chicano folklore in the third person narration. The use of very long sentences with multiple subordinate clauses that reminds us of the rhetoric of Spanish reappears in the narrative style of So Far from God.

Another recurrent technique that subverts a univocal message of these texts is the rupture of ethnographic narration. Common ethnography is a widely spread technique to represent the ethnic other through the description of cultural practices such as religious rites, customs, recipes, and any sort of exotic account of what is peculiar and therefore, different about a particular culture. So Far From God presents a large array of New Mexican traditions and customs inserted in the narration as additional spice that gives the text a quasimagical realistic flavor that easily enchants the Anglo reader. However, the narration is repeatedly interrupted by unexpected episodes that contradict the supposed function of a text that is a product of marketable multiculturalism. Some of these episodes appear as harsh criticism against institutional practices like the exploitation of Chicano/Mexican American workers exemplified in the tragic intoxication with chemicals that one of the characters suffers, as feminist statements against violent practices towards women or as subtle defense of lesbian desire like in the case of Caridad. It is interesting to observe that the narrator proves to be unreliable, ambivalent and frequently contradictory to the text itself. On the one hand, ethnographic accounts are narrated by someone who seems to be aware of his/her eminently non-Latino reader as when he/she teaches the reader about Spanish expressions or traditions as in the chapter devoted to Doña Felicia's remedios like 'aigre,' explained in a long paragraph (67). However, some other times the narrator is not as tactful and considerate towards the Anglo ignorant reader provoking sentiments of discomfort and even annoyance as when derogatory terms such as 'gringo' or 'gabacha' are used: 'Doña Severa was particularly proficient at curing 'suspension,' an ailment unknown to gringos and which has no translations" (234). Therefore, this ambivalent narrator seems to comply to the reader's expectation of 'ethnic color' while at the same time he/she betrays the text's supposedly marketable status defying the comfortable position of a reader who does not take the trouble of considering how it feels to be ethnic and different. 
Similar techniques of double messages encoded within the narrative techniques can be observed in When I Was Puerto Rican by Esmeralda Santiago and The Line of the Sun by Judith Ortiz Cofer. The first half of both works are completely devoted to ethnographic accounts of life in the island of Puerto Rico. These accounts include colorful descriptions of the landscape in a language that resembles that of the Latin American boom narratives: detailed explanations of particular practices such as the velorios, the quinceañera celebration, etc. Both works center around the figure of the jibaro a country peasant whose exotic appeal diminishes as the narration develops. In The Line of the Sun, the style becomes complex and baroque in an attempt to match the Spanish background from which the story and the magic that surrounds the events emerge. The account of Tío Guzmán's life in the island gradually becomes a sad story that does not match the marvelous landscape where it takes place. The magic halo is finally substituted by the gray atmosphere of the big American city, paved streets, and cold weather. It is at this moment when the style becomes direct, strikingly concrete and simple while the syntax increasingly resembles now the structure of English, a more appropriate language to relate the American experience. In When I was Puerto Rican, Santiago similarly makes use of extensive ethnographic accounts but interestingly enough, she inserts scattered comments and references to a world that does not match the reader's expectations. The narration of Negi's family's life in rural Macún describes images of children sleeping in hammocks in contact with a wild nature, however, references to Korea, to the fight for independence in Puerto Rico and the American invasion, for instance, are spread all over the first half of the book as clear elements of narrative rupture. The recurrence of this type of technique destabilizes the reader's expectation and prepares him/her for the transformation that the narrative itself undergoes in the second half. It is important to notice how these writers make clear the development of their own discourse from a one culture to the other, not becoming either of them but redefining both: the island is not a paradise and though the reader is given colorful description of exotic places and people, they immediately clash with the real nature of this people, their poverty, and their humanity. As Marisol and Negi, the main characters in both works, grow up, they suffer a transformation from exotic others to common Puerto Rican-American women. Their lives become similar to that of most Americans but they have been able to remove the mask of difference and otherness that commodifies them.

Another common technique is that of playfulness and parody. Humor is indeed a powerful instrument of criticism that is not ignored by Latina writers. Sometimes the ethnic experience is so exaggerated and distorted that individuals are presented as clown-like figures that lose any stability. One of the masters of humor among Latina writers is undoubtedly Julia Alvarez, a Dominican-American writer who not only makes extensive use of multiple narrators and points of view that destabilize a central and dominating discourse or narration of the events. Her use of humor is so subtle and successful that both cultures fall under her ironic and critical eye. For instance, in Yo! Dexter Fisher, the protagonist's suitor is subject to innumerable comic situations where his own expectations are deemed silly and irisory as he fights to understand Yo and her Dominican culture:

Dexter's time is coming. He can feel it in the air. This Yo Lady is Missus Right, all right. Another maverick, another fly-by-the-seat-of-your-pants person with the added pizzazz of 
being Latin. In the movies Spanish ladies have roses tucked behind their ears and low-cut peasant blouses with little crucifixes like hexes above those heaving bosoms, yeah! They met at a rally in support of Nicaragua or maybe it was Cuba ... at these rallies there are naturally lots of natives from these countries, and Dexter has always had a weak spot for Latin women. Yo is right up his ethnic alley. (189)

These sorts of commentaries alluding to Anglo ignorance about ethnic people and their reliance on stereotypes become much more problematic when they constantly reappear in Latina narratives. In the chapter "the suitor," Alvarez plays with the idea of lack of mutual understanding between cultures. As Yo comments about her writing and life in the island, what is exotic, magical and attractively unbelievable can be crudely true within the other's culture:

It's all one big story down here, anyway. The aunts all know that their husbands have mistresses but they act like they don't know. The president is blind but he pretends he can see. Stuff like that. It's like one of those Latin American novels that everyone thinks is magical realism in the States, but its the way things really are down here." (197)

For a moment Dexter is supposed to substitute the Anglo reader who realizes the other's life and culture is not what he/she supposed to be but something much more complex that requires a more respectful and deep understanding: "Suddenly the world seems very complicated, a world which is not simply black and white, but a shifting interplay of shadows, so unlike Dexter's bright lights and rocket's red glare" (195). The apparently uncomplicated world of Caribbean exoticism that Anglo readers like Dexter would easily expect from the book and its cover become more complex as the text itself challenges those expectations and its very construction. The text reflects the complexity of ethnic experience in the United States in the case of a Dominican American writer, the protagonist Yo, who is not merely a colorful element in American society but a person whose identity emerges out of different cultures, out of multiple discourses that are sometimes dominate and other times minoritarian. Alvarez's text makes fun of some of the assumptions upon which the dominant discourse rests in an attempt to provoke a reaction, to awaken the need to be critical towards institutional practices to contain ethnic difference.

The representation of the complexity of the Latino experience in the United States as a reaction to multiculturalist intrusion through difference is also masterfully acknowledged by techniques such as the use of multiple narrators and perspectives. In a very postmodernist way, narratives such as Dreaming in Cuban by Cristina Garcia or How the Garcia Girls Lost Their Accents by Julia Alvarez defy the existence of a dominant narrative voice that monopolizes the interpretation of events and imposes a univocal attitude towards very complex issues such as the Cuban revolution or the dictatorship of Trujillo in the Dominican Republic. Garcia's work is the most successful one at rejecting this unifying narrative perspective. Dreaming in Cuban finds its admirable textual balance thanks to the insertion of different narrators who present opposing and favoring views about the Cuban revolution. The use of so many different narrators and the overall political ambiguity that surrounds the text mainly responds to two almost contradictory objectives. On the one hand, Cuban readers from both sides are expected to identity with some of the narrators depending on their political ideas and their experience of the Cuban revolution. In this way, the text allows 
very different readings of the same text and subsequently very different interpretations of the same event. On the other hand, mainstream readers are challenged by a text which is uncommonly ambiguous and politically impartial. Thus, a determinant event in the lives of Cubans in the island and in the mainland such as the Cuban revolution, is problematized in an attempt to provoke a more thoroughly reflection upon the dangers of extremist attitudes on both sides. The new generation of Cubans represented by Pilar, are the ones allowed a first person narration in the novel as the in-between voice that is presently promoting a more respectful view towards the Cuban experience and condemning the manipulative use of political issues for the benefit of those in a dominant position.

Throughout this brief survey of some Latina writer's works we have tried to show new ways to fight Latino commodification and to unveil the pros and cons of the multicultural craze. Though it is true that these writers belong to what has received the already familiar name of "Latino boom" they collaborate in a project that the Chicano artist and cultural theorist Guillermo Gomez Peña began to outline in 1898 in "The Multicultural Paradigm: An Open Letter to the National Arts Community." This project is one in which Latino artists fight against the manipulation of the Latino presence in the United States and an attempt to represent from within what Latinos and Latinas are really:

We want understanding not publicity. We want to be considered intellectuals, not entertainers; partners, not clients; collaborators, not competitors; holders of a strong spiritual vision, not emerging voices; and above all, full citizens, not exotic minorities. (52)

As we have observed, Latina writers are quite aware of the advantages of the boom in order to advance in this project where the means need to be subtle so as not to disturb the dominant gaze but they also need to make their message emerge from the text and finally provoke a reaction. Furthermore, these writers are extremely conscious of the paradoxes and contradictions of their own situation as fashionable ethnic writers who try to express similar contradictions and instability of the Latino subject stranded between cultures. Thus, these writers are playing the other's game, using their own instruments, their language, putting it all upside down so as to explain what they are by telling what they are not and making fun of what the non-Latinos expect them to be. As Peña comments: "Entonces la idea ya no es hablar sobre nosotros en una manera didáctica para buscar la aceptación, but rather to turn the table 360 degrees and begin anthropologizing the other . . . it's like making a parodic, dramatic and humorous theatre out of dominant fantasy. . ." (Kraniauskas 170). This is what Latina narrative is doing in a very subtle way. They may be marketable products for the outside observer but once inside the text, the use of some of the techniques we have mentioned makes these works become double-edged swords, postmodern products of an era where nothing is what it seems to be.

\section{WORKS CITED}

Aparicio, Frances, and Susana Chavez-Silverman, eds. Tropicalizations. Transcultural Representations of Latinidad. Hanover and London: U P of New England, 1997.

Bhabha, Homi. The Location of Culture. New York: Routledge, 1994. 
Castillo, Ana. So Far from God. New York and London: Penguin, 1994.

Cisneros, Sandra. Woman Hollering Creek. New York: Vintage Books, 1991.

Gates, Henry Louis. Loose Canons: Notes on the Culture Wars. New York: Oxford, 1992.

García, Cristina. Dreaming in Cuban. New York: Ballantine Books, 1992.

Gómez Peña, Guillermo. Warrior for Gringostroika. Saint Paul, Minn.: Greywolf Press, 1993.

Kraniauskas, John. "Border Dialogue: Talking to Guillermo Gómez Peña.” Travesia: Journal of Latin American Studies 3.1-2 (1995): 5-13.

McCracken, Ellen. New Latina Narrative: The Feminine Space of Postmodern Ethnicity. Tucson: The U of Arizona P, 1999.

Ortiz Cofer, Judith. The Latin Deli: Prose and Poetry. Athens and London: The U of Georgia $\mathrm{P}, 1993$

Santiago, Esmeralda. When I Was Puerto Rican. New York: Vintage, 1993.

Steele, Shelby. "The New Sovereignty: Grievance Groups Have Become Nations unto Themselves." Harper's Magazine July (1992): 47-54. 
